\title{
The early history of our understanding of the functions of the spinal cord
}

\author{
Jaspreet Johal $^{1} \cdot$ Marios Loukas $^{1} \cdot \operatorname{Rod}$ J. Oskouian $^{2} \cdot$ R. Shane Tubbs ${ }^{2}$
}

Received: 2 August 2017 / Accepted: 3 August 2017 /Published online: 12 August 2017

(C) Springer-Verlag GmbH Germany 2017

\section{Introduction}

Understanding of the structure and function of the spinal cord has historically been more reliably founded than theories on the function and physiology of other parts of the body. Oftentimes, vague hypotheses proposed as facts for various physiological and anatomical structures were accepted without any verifiable experimental results [1]. Given the morphological consistency displayed by the spinal cord and the obvious clinical symptoms and syndromes produced from injury to it, the function and actions of the spinal cord were not the subject of conjecture and scientific uncertainty. Contemporary research on the spinal cord has instead focused on microanatomy and manipulation of the spinal cord to treat spinal cord injury [2]. The present review aims to provide an overview of our understanding of spinal cord function through history, and how this historical understanding may be used to construct a framework to guide further research into spinal cord function.

\section{Historical understanding of spinal cord function}

As mentioned above, the structural consistency and relative ease of access and manipulation of the spinal cord has allowed for our understanding of its function to have been well

R. Shane Tubbs

shanet@seattlesciencefoundation.org

1 Department of Anatomical Sciences, St. George's University, True Blue, Grenada

2 Seattle Science Foundation, 55017 Ave. Suite 600, Seattle, WA 98122, USA established even by early physicians. Writings from Hippocrates have also provided information on the clinical consequences of injury to the spinal cord $[1,3]$. The eleventh century physician Ibn Jazlah posited that diseases of the spinal cord appeared to result in paralysis and numbness. He further noted that lesions of the beginning of the spinal cord appeared to cause injury to the limbs of the body but did not involve the face. He also noted that other associated symptoms included tremor and limited movements [4]. These are just few instances of early physician scientists noting the correlation between spinal anatomy and the stereotypic symptoms produced from injury to the spine.

These correlations were somewhat verified by experimental investigation of the spine via irritation of various components of the cord and then correlating manipulation to specific symptoms and lesions [1]. This approach was pioneered by Galen and stayed at the same stage of development until the end of the eighteenth century. Galen, and other historical scientists, established a functional relationship between the brain and spinal cord. Galen believed the spinal cord to be a conductor of sensorimotor signals that conveys messages to and from the brain, and compared it to a stream that gushes out of the brain and sends nerves to all parts of the body. Other historical scientists also commented on the relationship between the brain and the spinal cord. The third century BC Greek Praxagoras hypothesized that the brain was only a continuation of the spinal cord, and Aristotle believed that the spinal cord is rich in blood and of a hot nature. Willis proposed that the spinal cord exists as the main route for "life spirits" formed within the brain $[1,5]$.

Early experiments on insects and cold-blooded animals were also important in establishing the significance of the spinal cord. These researchers found that decapitation of some species of animal models may preserve sensory and motor faculties whereas these abilities were lost following lesioning 
of the spinal cord. They concluded that the spinal cord should perhaps be assigned a more important role than even the brain. These conclusions were proposed by early scientists such as Redi and Swammerdam [1, 6]. Swammerdam noted that this primarily occurred in insects, and hypothesized that the brains of insects were too small and poorly developed to be able to coordinate all of their complex muscle movements.

Pathology of the spinal cord has also been described in historical medical texts, dating back to Hippocrates (Fig. 1 and cover figure) and his immediate disciplines. These Hippocratic physicians associate injury of the spinal cord with symptoms such as paralyses, spasms, and disruptions of urinary bladder emptying. The ancient Greek Celsus (second century) (Fig. 1 and cover figure) described a syndrome of paralysis of the arms, convulsions, pain, vomiting, and difficulty breathing following fractures associated with the upper spinal column. Injuries of the lower spinal column were associated with paralysis of the legs and disruption of urinary voiding $[1,7]$. The experimental approach pioneered by Galen (Fig. 1 and cover figure) yielded further clarification on the pathological sequelae of spinal cord injury. His studies led credence to the notion that

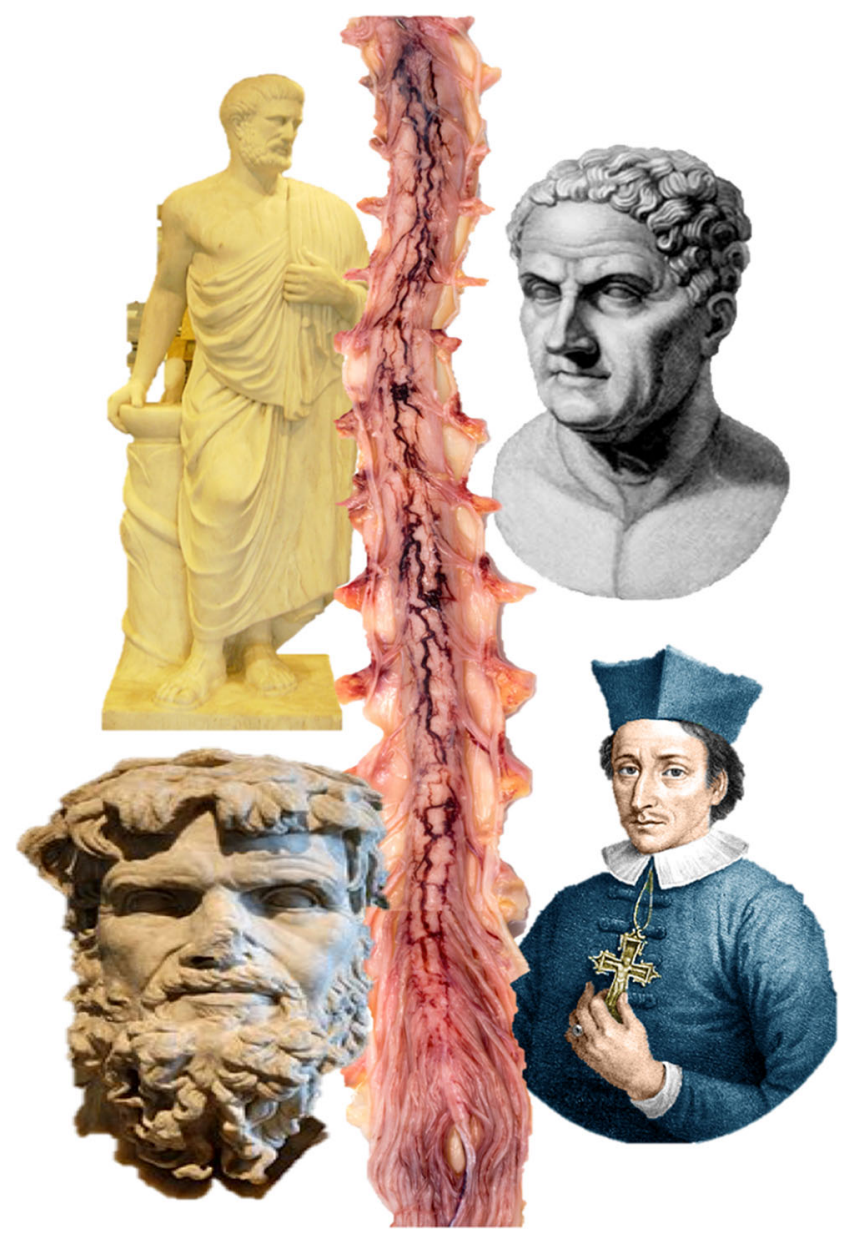

Fig. 1 and cover figure Collage demonstrating physicians who have studied the spinal cord over human history. From left to right and clockwise, Hippocrates, Galen, Steno, and Celsus damage to the spinal cord at a particular level will disrupt sensory and motor function at locations below the level of the lesion. Animal studies conducted by Galen also showed that hemisection of the spinal cord only seemed to impact the ipsilateral side of the body, and that midline, longitudinal sectioning did not produce any significant paralysis. Galen's interventional experiments on animal models also showed that injury to certain locations of the spinal cord could disrupt important physiological processes, such as breathing. Significantly, he reported that sectioning between the third and fourth cervical levels lead to cessation of thoracic respiratory movements, as well as all movements lying below the lesion [1].

Surgical exploration and dissection gradual gained prominence as a research technique for human anatomy; however, no novel insight into function of the spinal cord was gained in the early stages of this approach. Significant findings of fifteenth to seventeenth century anatomists instead focused on anatomy of the brain and vagus nerve. In 1667, the Dane Steno (Fig. 1 and cover figure) ligated the descending aorta and produced paralysis of the lower extremities and rightfully attributed this to ischemia of the spinal cord [1, 8]. Early anatomists and physicians likely did not differentiate between injury to the medulla oblongata and the spinal cord, and felt that injury to the spinal cord could lead to rapid death. Researchers such as Perrault declared the spinal cord to be the most vital component of the central nervous system [1, 9]. The technique of stimulating and irritating specific segments of the spinal cord soon became common, with electrical stimulation being introduced in the mid-eighteenth century by van den Bosch $[1,10]$. Stimulation of the spine often yielded local convulsions and movements, but this approach did not initially establish any concrete functional relationships.

\section{Conclusion}

The methods and techniques used for exploration of the spinal cord progressively became more invasive but this did not necessarily yield novel discoveries into functions of the spinal column. This may have been in part due to lack of knowledge on the histological details of the structure and segmentation of the spinal column. Without this knowledge, the cord was experimented upon as a singular, consistent structure. As we now know, the spinal cord has a highly segregated anatomy and lack of insight into the spine's detailed anatomy prevented researchers from describing its specific functions. Through clinical correlations between both symptoms and lesions of the spine, along with early manipulative investigations, historical researchers were able to identify the spinal cord as an important conduit for signals to and from the brain. Contemporary researchers $[2,11-17]$ have used investigative techniques that have gone beyond surgical manipulation and stimulation to visualize the various components of the central 
nervous system; however, a great amount of effort and research is still needed to map and decipher the intricacies of the human spinal cord.

\section{Compliance with ethical standards}

Conflict of interest The authors have no conflicts of interest.

\section{References}

1. Clarke E (1981) The historical development of experimental brain and spinal cord physiology before Flourens. The Johns Hopkins University Press, Baltimore. Translated from: Neuburger M (1897) Die historische Entwicklung der experimentellen Gehrinund Ruckenmarksphysiologie vor Flourins. Stuttgart: Ferdenand Enke Verlag

2. Mortazavi MM, Verma K, Harmon OA, Griessenauer CJ, Adeeb N, Theodore N, Tubbs RS (2015) The microanatomy of spinal cord injury: a review. Clin Anat 28:27-36

3. Withington ET (1927) Hippocrates On joints, XLVIII. In: Withington ET (ed) Hippocrates with an English translation, vol. 3. W. Heinemann, London, pp 302-307

4. Tubbs RS, Loukas M, Shoja MM, Ardalan M, Oakes WJ (2008) Ibn Jazlah and his 11th century accounts (Taqwim al-abdan fi tadbir al-insan) of disease of the brain and spinal cord. Historical vignette. J Neurosurg Spine 9:314-317

5. Willis T (1664) Cerebri anatome: cuir accessit nervorum descripito et usus. J. Martyn \& J. Allestry, London

6. Swammerdam J (1738) Bybel der nature histoire der insekten, Boerhaave H, Gaubu HD. Leyden I. Severinus, p 855
7. Celsus AC (1938) In: Spencer WG (ed) De medicina, with an English translation, vol. 3. W. Heinemann, London, pp 566-569

8. Steno N (1667) Elementorum myologiae specimen, seu musculi description geometrica. Stella, Florence

9. Perrault C, Perrault P (1721) Oeuvres diverses de physique et de mechanique, 2 vols. P. Vander, Leyden

10. van den Bosch IJ (1757) Specimen physiologico-medicum inaugurale. De vivis humani corporis solidis. SJ Luchtmans \& N Moens, Leyden

11. Arya NG, Weissbart SJ (2017) Central control of micturition in women: brain-bladder pathways in continence and urgency urinary incontinence. Clin Anat 30:373-384

12. Turkoglu E, Kertmen H, Uluc K, Akture E, Gurer B, Cikla U, Salamat S, Başkaya MK (2015) Microsurgical anatomy of the posterior median septum of the human spinal cord. Clin Anat 28:45-51

13. Mortazavi MM, Harmon OA, Adeeb N, Deep A, Tubbs RS (2015) Treatment of spinal cord injury: a review of engineering using neural and mesenchymal stem cells. Clin Anat 28:37-44

14. Griessenauer CJ, Raborn J, Foreman P, Shoja MM, Loukas M, Tubbs RS (2015) Venous drainage of the spine and spinal cord: a comprehensive review of its history, embryology, anatomy, physiology, and pathology. Clin Anat 28:75-87

15. Hendrix P, Griessenauer CJ, Cohen-Adad J, Rajasekaran S, Cauley KA, Shoja MM, Pezeshk P, Tubbs RS (2015) Spinal diffusion tensor imaging: a comprehensive review with emphasis on spinal cord anatomy and clinical applications. Clin Anat 28:88-95

16. Bosmia AN, Tubbs RS, Hogan E, Bohnstedt BN, Denardo AJ, Loukas M, Cohen-Gadol AA (2015) Blood supply to the human spinal cord: part II. Imaging and pathology. Clin Anat 28:65-74

17. Bosmia AN, Hogan E, Loukas M, Tubbs RS, Cohen-Gadol AA (2015) Blood supply to the human spinal cord: part I. Anatomy and hemodynamics. Clin Anat 28:52-64 